\title{
Radium inputs into the Arctic Ocean from rivers: a basin-wide estimate
}

\author{
EMMA J. BULLOCK ${ }^{1}$, JESSICA S. DABROWSKI ${ }^{1}$, \\ LAUREN E. KIPP ${ }^{2}$, KRISTINA A. BROWN ${ }^{3}$, PAUL MANN ${ }^{4}$, \\ PAUL B HENDERSON ${ }^{1}$, WILLARD MOORE ${ }^{5}$ AND \\ MATTHEW A CHARETTE ${ }^{1}$
}

${ }^{1}$ Woods Hole Oceanographic Institution

${ }^{2}$ Rowan University

${ }^{3}$ Institute of Ocean Sciences

${ }^{4}$ Northumbria University

${ }^{5}$ University of South Carolina

Presenting Author: ebullock@whoi.edu

Radium $(\mathrm{Ra})$ isotopes are powerful tracers of groundwater and shelf inputs into the ocean, which are important sources of nutrients, carbon, and trace metals. However, quantifying these inputs requires an understanding of all other $\mathrm{Ra}$ sources to the coastal ocean, including rivers. The net ocean input of $\mathrm{Ra}$ isotopes from rivers must consider the freshwater dissolved load, as well as $\mathrm{Ra}$ desorbed from suspended particles in river estuaries. Furthermore, $\mathrm{Ra}$ in rivers depends on watershed hydrogeology, suspended sediment concentration and grain size, and temperature. This means that river $\mathrm{Ra}$ fluxes cannot be determined by river discharge and dissolved concentrations alone.

This study aims to estimate river Ra inputs into the Arctic Ocean. We present the first Ra desorption data for the Eurasian Arctic from samples taken in the Kolyma River. Using these values, together with data from the Mackenzie River and other rivers in Canada, we derive independent estimates of desorbed 228-Ra and 226-Ra for the North American and Eurasian Arctic regions, as well as the dissolved Ra flux into the Arctic Ocean. Finally, we attempt to put these data in the context of global river $\mathrm{Ra}$ inputs, combining literature values for dissolved and desorbed $\mathrm{Ra}$ and river discharge with new data from six North American high-latitude rivers. As climate change spurs rapid warming in the Arctic, thawing permafrost and diminishing ice cover will likely increase groundwater and shelf inputs. The need for a baseline of river $\mathrm{Ra}$ inputs to the Arctic Ocean will become increasingly more important as we attempt to understand the changes that warming temperatures are having on fluxes of biogeochemically important elements to the coastal zone. 